\title{
An Intra-strain Conjugation System of a Specific Serotype of Escherichia coli $\mathrm{O} 4$
}

\author{
By L. ZUBRZYCKI, D. SIEGEL* AND MARIA CHILLEMI \\ Department of Microbiology and Immunology, \\ Temple University School of Medicine, Philadelphia, Pennsylvania, 19r40, U.S.A.
}

(Received 5 October I973; revised I8 March I974)

\begin{abstract}
SUMMAR Y
Donor and recipient strains were isolated from a single clinical isolate of an Escherichia coli $\mathrm{O} 4$. Strain $\mathrm{Z} 20$ is a low-frequency donor which transfers a variety of markers to the recipient strain, CF2004-6. However, the recombination frequency for the tryptophan marker occurs at a somewhat higher frequency. The fact that all recombinants become donors and donor ability can be temporarily derepressed, suggests that this intra-strain conjugation system depends upon a repressed sex factor, termed the $\mathrm{Z}$ factor. When a lysogenic donor strain is used, the phage genome also is transferred during conjugation to a majority of the recombinants. This leads to a state of 'transient lysogeny' in which all recombinants segregate non-lysogens.
\end{abstract}

\section{INTRODUCTION}

Bacterial conjugation was first discovered with Escherichia coli strain $\mathrm{KI} 2$ (Lederberg \& Tatum, 1946). This mating system is dependent upon the function of a sex factor, called $F$, in the donor. Sex-factor-mediated transfer of chromosomal genes is widespread among members of the family Enterobacteriaceae (Meynell, Meynell \& Datta, I968; Novick, I969), and is also found in Pseudomonas (Holloway, Krishnapillai \& Stanisich, I97I) and Vibrio (Bhaskaran, I960; Bhaskaran \& Sinha, 197I).

We became interested in a fertility system of an $E$. coli when we fortuitously isolated donor and recipient strains from a clinical isolate. In this communication we show that this conjugation system has some characteristics of the conjugation systems already mentioned, and others of its own. A preliminary report on some of this work has already been made (Siegel \& Zubrzycki, 1968).

\section{METHODS}

Media. These were as described by Zubrzycki, Green \& Spaulding (1966).

Bacteria and phages. The donor, $\mathrm{Z} 2 \mathrm{O}$, and recipient, $\mathrm{CF} 2004-6$, are strains of a particular clinical isolate of Escherichia coli $\mathrm{O}_{4}: \mathrm{K}$ (undetermined): $\mathrm{H}_{5}$, hereafter referred to as E. coli $\mathrm{O}_{4}$. Derivatives of these strains and others are listed in Table I.

Mating techniques. Cultures of the recipient were grown in broth until the population reached $5 \times 10^{8}$ to $8 \times 10^{8}$ bacteria $/ \mathrm{ml}$, centrifuged and the resulting pellet resuspended in saline $(0.85 \%, \mathrm{w} / \mathrm{v})$ at a fifth or tenth of the original volume. Mating mixtures were made by combining equal volumes of the suspension of the recipient and a young broth culture of the donor $\left(5 \times 10^{8}\right.$ to $8 \times 10^{8}$ bacteria $\left./ \mathrm{ml}\right)$. Portions $(0.2 \mathrm{ml})$ of the mating mixture were spread immediately on the appropriate minimal agar. The auxotrophic donors were

* Present address: Department of Pharmacology and Physiology, School of Veterinary Medicine, University of Illinois, Urbana, Illinois, 61801, U.S.A. 


\begin{tabular}{ll}
$\begin{array}{c}\text { Strain } \\
\text { designation }\end{array}$ & \multicolumn{2}{c}{ Strain origin } \\
Z2O-I & Z2O \\
Z2O-IS & Z2O-I \\
Z2O-I I & Z2O-I \\
MR I9-I & A CF2004-6 recombinant from a \\
& mating with Z2O-I \\
M3-3 & A CF2004-6 recombinant from a \\
& mating with Z2O-I \\
L6 & CF2004-6 \\
L6-6I & L6 \\
& \\
L6-I & CF2004-6 \\
LZ-TM-5 & CF2004-6 \\
LZ-TM-9 & LZ-TM-5 \\
Ra3 & LZ-TM-9 \\
CTM-4I & CF2004-6
\end{tabular}

\section{Table I. Strains of bacteria used}

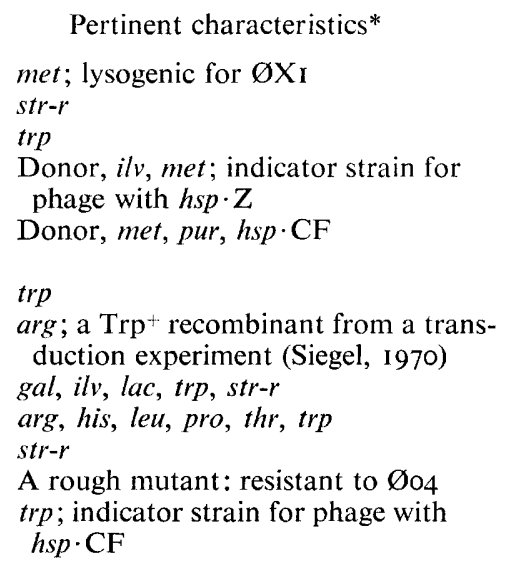

* Markers and characteristics irrelevant to the experiments being presented are not listed. The markers of the donors are listed in order to indicate how they were counterselected in conjugation experiments. Unless indicated, the strains listed have the same markers as those from which they were derived.

effectively counterselected by the absence of appropriate nutrient(s) in the agar. Plates were incubated for approximately $48 \mathrm{~h}$ at $37^{\circ} \mathrm{C}$ before scoring the recombinants.

Other mating experiments were carried out on filters. A $\mathrm{r}$ ml mating mixture was filtered onto a sterile $25 \mathrm{~mm}$ Millipore filter, type $\mathrm{HA}$, and the filter was placed on the surface of a warm $\left(37^{\circ} \mathrm{C}\right)$ tryptic soy agar plate (Difco). The plate with the filter was incubated at $37^{\circ} \mathrm{C}$. After incubation, the filter was placed in a sterile $25 \times 150 \mathrm{~mm}$ test tube containing $2 \mathrm{ml}$ saline. The mating mixture on the filter was suspended in the saline by vigorously agitating on a Vortex-Genie (Scientific Industries, Inc., Springfield, Massachusetts, U.S.A.), at top speed, for approximately I min. This suspension was then used for plating recombinants or subsequent procedures, as described in the text.

Unselected marker analyses. Colonies were picked with sterile toothpicks and streaked as small patches onto nutrient agar plates. After 8 to $12 \mathrm{~h}$ of incubation, the patches were replica-plated onto appropriate minimal medium agar plates to score for unselected markers.

Ultraviolet irradiation. A young broth culture was centrifuged, the pellet suspended in phosphate buffer and subjected to an u.v. source at $70 \mathrm{~cm}$ distance, as previously described (Zubrzycki et al. I966).

Notation and abbreviations. The abbreviations for genetic markers conform to the recommendations of Demerec, Adelberg, Clark \& Hartman (1966). They are: arg (arginine), gal (galactose), his (histidine), hsp (host specificity), ilv (isoleucine), lac (lactose), leu (leucine), met (methionine), pro (proline), pur (purine), str (streptomycin; $r$ for resistant, $\mathrm{s}$ for sensitive), $t h r$ (threonine) and $t r p$ (tryptophan). The notation to designate the $h s p$ of the host is based on that used by Arber \& Linn (1969). Hsp.CF denotes the host specificity of the CF2004-6 strains and $h s p \cdot Z$ that of the $z 20$ strains. 
Table 2. Inheritance of unselected markers from a cross between Z2O-I and LZ-TM-9

\begin{tabular}{|c|c|c|c|c|c|c|c|}
\hline \multirow{2}{*}{$\begin{array}{l}\text { Recon- } \\
\text { binants } \\
\text { selected }\end{array}$} & \multirow{2}{*}{$\begin{array}{l}\text { Number of } \\
\text { recombinants } \\
\text { tested }\end{array}$} & \multicolumn{6}{|c|}{ Percentage of recombinants with unselected markers from $\mathbf{2 2 0 - I}$} \\
\hline & & $t r p$ & pro $^{+}$ & $\mathrm{leu}^{+}$ & $t h r^{+}$ & $\arg ^{+}$ & his \\
\hline $\operatorname{Trp}$ & I 24 &.-- & 0 & 0 & o & 0 & 0 \\
\hline Pro & 149 & 0 & 一 & $6 \cdot 7$ & 5.4 & 0 & 0 \\
\hline Leu & 139 & o & $7 \cdot 2$ & - & $4 \cdot 3$ & 0 & 0 \\
\hline Thr & 223 & 0 & I $\cdot 8$ & II & - & 0 & 0 \\
\hline $\mathrm{Arg}^{+}$ & 128 & 0 & 0 & 0 & 0 & - & 0 \\
\hline $\mathrm{His}^{+}$ & 24 I & 0 & 0 & 0 & 0 & 0 & - \\
\hline
\end{tabular}

Table 3. Numbers of Trp ${ }^{+}$recombinants selected on agar with or without streptomycin from crosses with one parent streptomycin-sensitive and the other streptomycin-resistant

\begin{tabular}{|c|c|c|c|}
\hline \multirow[b]{2}{*}{ Cross } & \multirow[b]{2}{*}{ Mating pairs } & \multicolumn{2}{|c|}{ Numbers* } \\
\hline & & $\begin{array}{l}\text { Without } \\
\text { streptomycin }\end{array}$ & $\begin{array}{c}\text { With } \\
\text { streptomycin }\end{array}$ \\
\hline I & $\mathrm{Z} 2 \mathrm{O}-\mathrm{IS}(s t r-r) \times \mathrm{LZ}-\mathrm{TM}-5(s t r-s)$ & I 9480 & o \\
\hline 2 & Z2O-I $($ str-s $) \times$ LZ-TM-9 $(s t r-r)$ & 15680 & 42 \\
\hline
\end{tabular}

* These are average colony counts from eight plates, adjusted to correspond to plating of the undiluted mixture.

\section{RESULTS}

\section{Polarity of transfer}

Preliminary experiments suggested that strains of $\mathrm{Z} 20$ were donors and strains of CF2004-6 were recipients in an intra-strain conjugation system. All recombinants tested were stable for a variety of single and multiple markers. The following is proof that there is this polarity of transfer during conjugation: matings between a variety of auxotrophic mutant strains of CF2004-6 were sterile, but matings between auxotrophic mutants of z2O were productive. Recombinants from a mating between Z20 and CF2004-6 auxotrophs retained most of the markers of the CF2004-6 auxotroph. These results are shown in Table 2 from a mating using LZ-TM-9 as the recipient.

Finally a Hayes type of experiment (Hayes, 1952a) was carried out, using streptomycin to demonstrate polarity of transfer between mutants of z2O and CF2004-6. Because plating a mating mixture immediately on streptomycin-containing agar inhibits the formation of recombinants, the matings were done on Millipore filters which were incubated overnight on nutrient agar. The filters were washed in $2 \mathrm{ml}$ saline and dilutions were plated on minimal medium agar (with or without streptomycin) to score for $\operatorname{Trp}^{+}$recombinants. Differential counts of the donors and recipients were made and were found to be essentially the same, about $\mathrm{I} \times 10^{9}$ to $3 \times 10^{9} / \mathrm{ml}$.

The results (Table 3) indicate that $\mathrm{Z} 20$ is a donor and CF2004-6 is a recipient. Note, in cross 2 , that there are more recombinants on the agar without streptomycin than on agar with streptomycin. This suggests that matings continue to occur for some time period after plating. Consistent with this is the observation that the colonies of the recombinants on the plain agar varied greatly in size, in contrast to the relatively uniform size of the colonies on the streptomycin-containing agar. Approximately 800 recombinant colonies from streptomycin-containing or plain agar plates were checked and all were found to be $\operatorname{Trp}^{+}$recombinants of LZ-TM-9. Similar experiments were carried out with two other derivatives of Z20 
Table 4. Recombinant frequencies for different markers from a cross between Z2O-I and two multiply-marked mutants of CF2004-6

\begin{tabular}{|c|c|c|}
\hline \multirow[b]{2}{*}{ Markers } & \multicolumn{2}{|c|}{ Recipients* } \\
\hline & L6-I & LZ-TM-9 \\
\hline $\operatorname{trp}$ & $28 \times 10^{-4}$ & $2 \times 10^{-5}$ \\
\hline gal & $6 \times 10^{-6}$ & - \\
\hline pro & - & $7 \times 10^{-7}$ \\
\hline lac & $4 \times 10^{-7}$ & - \\
\hline leu & - & $5 \times 10^{-7}$ \\
\hline$t h r$ & - & $3 \times 10^{-6}$ \\
\hline arg & - & $5 \times 10^{-7}$ \\
\hline ilv & $2 \times 10^{-7}$ & - \\
\hline his & - & $2 \times 10^{-6}$ \\
\hline
\end{tabular}

${ }^{*}$ Frequencies of reversion for each marker were less than $10^{-8}$.

(MRI9-I and M3-3) and the results were essentially the same, namely, there were no recombinant colonies on the streptomycin-containing agar from cross I with str-s derivatives of CF2004-6.

\section{Frequency of recombination and linkage analyses}

Strain Z2O-I is a low-frequency donor. The frequencies of recombination using two different recipients are shown in Table 4. Of the markers scored, the frequency of recombination was highest for the trp marker. This observation has been made repeatedly.

\section{Transfer of plasmids during conjugation}

Using routine techniques for handling phage, it was found that z2O-I was immune to phage $\varnothing_{04}$, a generalized transducing phage specific for E. coli $\mathrm{O}_{4}$ (Zubrzycki et al. 1966). It was also found that $30 \mathrm{Il}^{+}$recombinants from a $\mathrm{Z2O}-\mathrm{I} \times \mathrm{L6}-\mathrm{I}$ mating were immune to Ø04. Overnight cultures of the recombinants were chloroform-treated and spotted on a lawn of CTM-4I, the indicator strain for Ø04. All spots were positive for phage. Subsequently it was established that Z2O-I is lysogenic for a phage, labelled $\varnothing \mathrm{XI}_{\mathrm{I}}$, which is a co-immune small plaque variant of Øం4.

To check whether phage could be isolated from recombinants for different markers, overnight broth cultures of recombinants were chloroform-treated and spotted onto a lawn of the phage indicator strain. The results were that 80 to I00 $\%$ of 445 recombinants for four different markers yielded phage. The plaque type was often a mixture of $\varnothing \mathrm{XI}_{\mathrm{I}}$ and $\varnothing_{04}$, but this mixture always occurs when an attempt is made to propagate phage ØXI. It was hypothesized that the phage genome was being transferred during conjugation. To test this, a rough strain, Ra3, which is a phage Øo4-resistant mutant of LZ-TM-9, was used in mating experiments. Since Z2O-I and CF2004-6 have different host specificities ( $h s p \cdot Z$ and $h s p \cdot$ CF respectively) for restriction and modification of Øо4 (Zubrzycki, Levinson \& Siegel, I 972) and ØXI (unpublished), the Ra3 recombinants should yield phage with hsp.CF.

From a plate mating with Z2O-I, 50 Trp ${ }^{+}$recombinants of Ra3 were selected and grown in broth. After chloroform treatment, the cultures were spotted on lawns of CTM-4I with $h s p \cdot$ CF and MRI9-I with $h s p \cdot \mathrm{Z}$. Thirty-four recombinants yielded an estimated 200 to more than I000 plaques on CTM-4I, but only a few plaques on MRI9-I, which it is known could be due to the incidental carryover of phage from the z2O-I spread on the recombination plate. The remaining 15 recombinants yielded low numbers of plaques on both phage 


\section{Table 5. The effects of u.v. irradiation on donor ability of \\ $Z^{+}$donor strains with different host specificities}

The subsequent mating was with L6-I and selection was for Trp ${ }^{+}$recombinants.

\begin{tabular}{|c|c|c|c|c|c|c|}
\hline Donor $\cdot h s p$ & $\begin{array}{l}\text { U.v. dose } \\
\text { (s) }\end{array}$ & $\begin{array}{l}\text { Survivors } \\
(\%)\end{array}$ & $\begin{array}{l}\text { Recombinants/ } \\
\mathrm{ml}\end{array}$ & $\begin{array}{l}\text { Increase } \\
\text { in re- } \\
\text { combinants/ } \\
\text { ml }\end{array}$ & $\begin{array}{l}\text { Recombinant } \\
\text { frequency }\end{array}$ & $\begin{array}{l}\text { Increase } \\
\text { in re- } \\
\text { combinant } \\
\text { frequency }\end{array}$ \\
\hline $\mathrm{M} 3-3 \cdot \mathrm{CF}$ & $\begin{array}{r}0 \\
20 \\
100\end{array}$ & $\begin{array}{c}100 \\
46 \\
0.2\end{array}$ & $\begin{array}{l}7 \cdot 7 \times 10^{2} \\
1 \cdot 2 \times 10^{4} \\
1 \cdot 5 \times 10^{3}\end{array}$ & $\begin{array}{l}- \\
\times 16 \\
\times 1 \cdot 9\end{array}$ & $\begin{array}{l}1 \cdot 9 \times 10^{-6} \\
6.3 \times 10^{-5} \\
2.5 \times 10^{-3}\end{array}$ & $\begin{array}{l}- \\
\times 33 \\
\times 1300\end{array}$ \\
\hline MRI9-I $\cdot Z$ & $\begin{array}{r}0 \\
20 \\
100\end{array}$ & $\begin{array}{c}\text { IOO } \\
47 \\
\text { O.I }\end{array}$ & $\begin{array}{l}4.8 \times 10^{3} \\
2.9 \times 10^{3} \\
1.3 \times 10^{2}\end{array}$ & $\begin{array}{l}- \\
\times 0.6 \\
\times 0.027\end{array}$ & $\begin{array}{l}3.0 \times 10^{-5} \\
3.9 \times 10^{-5} \\
1.9 \times 10^{-3}\end{array}$ & $\begin{array}{l}\times \\
\times I \cdot 3 \\
\times 65\end{array}$ \\
\hline
\end{tabular}

indicator strains, for reasons which will shortly become obvious. These results are consistent with the hypothesis that phage which is found in cultures of the recipient can be transferred from Z2O-I during conjugation.

With recombinants from recipients other than Ra3, there were fewer plaques than would have been expected from stable lysogenic cultures. To investigate this further, $60 \mathrm{Trp}^{+}$recombinants were selected from a mating between Z20-I and L6-I. Overnight broth cultures from all 60 yielded phage. The cultures were streaked onto minimal medium agar and isolated colonies were rechecked to determine whether they yielded phage. Two of the 60 recombinants segregated non-lysogenic and lysogenic clones; clones from the other recombinants were non-lysogenic. This observation has repeatedly been made: recombinants are only 'transiently lysogenized'. A rapid segregation of the phage genome and the fact that Ra3 cannot be secondarily infected with Øం4 could account for the low yield of phage in the 15 recombinants mentioned previously; a rapid segregation toward nonlysogeny could account for the few recombinant clones, also mentioned previously, which did not seem to yield phage.

In connection with the experiments on segregation of non-lysogenic recombinants, it was found that all $60 \mathrm{Trp}^{+}$recombinants were donors. Since then, from separate experiments, recombinants for a variety of other markers have also been found to be donors. However, the transfer of donor ability is not dependent on the transfer of chromosomal markers. After a $24 \mathrm{~h}$ Millipore-filter mating between M3-3 and L6-6I, the mating mixture was washed off the filter, diluted, and plated on minimal medium agar selective for recipients (not recombinants). The plates were incubated for approximately $24 \mathrm{~h}$ and then replicaplated onto an appropriate minimal medium agar plate pre-spread with L6-I, to select for $\mathrm{Trp}^{+}$recombinants. Up to $\mathrm{I} \cdot 4 \%$ (74 of 5400) of the colonies were able to transfer the $t r p^{+}$ marker. Similar results were obtained in repeat experiments using different donor strains. In conformity with other fertility systems, this infectious donor ability is being attributed to a sex factor, named the $\mathrm{Z}$ factor. The $\mathrm{Z}$ factor per se does not account for hsp. $\mathrm{Z}$, because $\mathrm{Z}^{+}$donors with $h s p \cdot \mathrm{CF}$ have been isolated.

\section{Effect of ultraviolet irradiation}

Hayes ( $1952 b$ ) observed that u.v. irradiation of $\mathrm{F}^{+}$bacteria before a mating experiment resulted in increased recombinant frequencies. To determine whether this is the case with the $\mathbf{Z}^{+}$donors, they were similarly treated. The results with two of these are shown in Table 5 . Although donors with $h s p \cdot \mathrm{Z}$ and $h s p \cdot \mathrm{CF}$ are equally susceptible to u.v. irradiation, the 
Table 6. The infectious spread of donor ability from Z20-I I after periods of secondary mating with L6-6I, which becomes a secondary donor which transfers the trp marker to $\mathrm{L} 6$ at the frequencies shown

\begin{tabular}{|c|c|c|}
\hline $\begin{array}{c}\text { Primary } \\
\text { mating } \\
\text { time } \\
\text { (h) }\end{array}$ & $\begin{array}{l}\text { Secondary } \\
\text { mating } \\
\text { lime } \\
\text { (h) }\end{array}$ & $\begin{array}{c}\text { Recombinants } \\
\text { secondary } \\
\text { donors* }\end{array}$ \\
\hline o & 0 & $5 \times 10^{-8}$ \\
\hline \multirow{4}{*}{4} & 10 & $3.5 \times 10^{-6}$ \\
\hline & 1.5 & $1 \cdot 3 \times 10^{-5}$ \\
\hline & 3 & $3.0 \times 10^{-5}$ \\
\hline & 4.5 & $3.6 \times 10^{-4}$ \\
\hline 20 & 0 & $4.2 \times 10^{-6}$ \\
\hline
\end{tabular}

* Viable counts of the secondary donor, L6-6I, were made using the appropriate minimal medium agar which counterselected the primary donor, $\mathrm{Z} 2 \mathrm{O}-\mathrm{I} \mathrm{I}$.

other effects are different. With increasing doses of u.v. irradiation, M3-3 shows an increase in the number of recombinants $/ \mathrm{ml}$ and a dramatic increase in recombinant frequency. Strain MRI9-I shows a decrease in the number of recombinants $/ \mathrm{ml}$ and a relatively slight increase in recombinant frequency. Similar differences have been observed using three other donors with $h s p \cdot \mathrm{CF}$ and two with $h s p \cdot Z$.

There is no obvious explanation for the great increase in recombinant frequencies after u.v. irradiation of donors with $h s p \cdot \mathrm{CF}$, without which their recombinant frequencies are lower than donors with $h s p \cdot Z$. These experiments were not designed to explore what appears to be a fundamental difference between donors with $h s p \cdot C F$ and with hsp $\cdot \mathrm{Z}$. They merely show that u.v.-irradiated $Z^{+}$bacteria behave as better donors, which is similar to the results obtained with $\mathrm{F}^{+}$donors.

\section{Derepression of the $Z$ factor}

The $\mathbf{Z}$ factor appears to be similar to most transmissible plasmids whose fertility functions are repressed (Meynell et al. 1968). After such a plasmid is transferred to a new cell, the fertility functions of that plasmid remain derepressed for a short period of time. These transiently derepressed cultures can readily be detected when the plasmid codes for a somatic function such as the production of colicin or resistance to antibiotics. The $\mathrm{Z}$ factor does not code for either of these functions (Siegel, 1970; Zubrzycki, unpublished observations). Therefore, derepression of the $Z$, factor could only be detected by observing an increase in the subsequent recombinant frequency, employing an approach similar to that used to encourage the infectious spread of the Col (Stocker, Smith \& Ozeki, 1963) and $\mathrm{R}$ (Watanabe, 1963) factors. In the following experiment, a trp mutant of Z20-I was used as a donor to assure that this primary donor could not account for the ultimate appearance of Trp ${ }^{+}$recombinants. The protocol called for a filter mating of Z20-I I and L6-6I.

Three sets of filters were prepared. The mating mixture on one set was washed off immediately and plated with $\mathrm{L} 6$ on appropriate minimal medium agar plates to select $\mathrm{Trp}^{+}$recombinants. Another set of filters was placed on nutrient agar, incubated at $37^{\circ} \mathrm{C}$ for $20 \mathrm{~h}$ and then similarly plated with $\mathrm{L} 6$ to select $\mathrm{Trp}^{+}$recombinants. A third set was incubated for $4 \mathrm{~h}$, a time during which a reasonable number of recombination events between Z2O-I I and L6-6I could be expected. After the $4 \mathrm{~h}$ period of incubation the primary mating mixtures were suspended in saline and diluted to approximately $10^{8}$ bacteria $/ \mathrm{ml}$. These mating mixtures were placed on a series of filters. The mating mixture from one set of filters was 
immediately plated for Trp recombinants. The other filters were incubated on nutrient agar for secondary mating times of $\mathrm{I} \cdot 5,3$ and $4 \cdot 5 \mathrm{~h}$, and then plated for Trp ${ }^{+}$recombinants. Diluting the primary mating mixtures, replacing the mixtures on filters and re-incubating for a secondary mating time are procedures analogous to those used to detect the infectious spread of $\mathrm{Col}$ and $\mathrm{R}$ factors. The results are shown in Table 6. As was expected, there was a significant increase in the frequency of recombination from $5 \times 10^{-8}$ after zero time to $3.5 \times 10^{-6}$ after $4 \mathrm{~h}$ of primary mating. Primary mating for $20 \mathrm{~h}$ did not result in a greater recombinant frequency. However, during the periods of secondary mating, the recombinant frequencies increased up to $3.6 \times 10^{-4}$ in $4.5 \mathrm{~h}$. These results suggest that the $\mathrm{Z}$ factor can be transiently derepressed.

\section{DISCUSSION}

The mating system of Escherichia coli $\mathrm{O}_{4}$ resembles others in several general ways (Meynell et al. 1968). There is sexual polarity. Donor ability is ordinarily repressed but can be transiently derepressed. The infectious nature of donor ability can be attributed to a sex factor which is called the $\mathrm{Z}$ factor. Genetic recombination for chromosomal markers occurs at a low frequency. But there are other characteristics of this mating system which are worth discussing.

Of the markers studied, the highest frequency of recombination is for the $t r p^{+}$marker. It may be that the $\mathrm{Z}$ factor has an affinity for this region of the chromosome. However, the data of linkage analyses (Table 2; Siegel, 1970) do not show that there is any gradient of transmission of markers starting at the tryptophan locus. To determine whether this is the case one must have a derepressed mutant of the $\mathrm{Z}$ factor which transfers the chromosome at a higher frequency. It was with such a mutant that Pearce \& Meynell (I968) were able to conclude that the R I sex factor has an affinity for the tryptophan region and transfers the chromosome in a counterclockwise direction. A high-frequency donor strain has not so far been isolated. The difficulty in isolating such a strain is due to the fact that the $\mathrm{Z}$ factor does not code for an easily scored function, such as resistance to antibiotics or production of colicin (Siegel, 1970; Zubrzycki, unpublished observations).

When Z2O-I, the lysogenic donor, is used in conjugation experiments, a majority of the recombinants are immune to $\varnothing_{0} 4$ and yield $\varnothing_{04}$ and/or $\varnothing_{\mathrm{I}}$ upon initial testing. This is only a transient state because the recombinants soon segregate non-lysogens. Possibly all recombinants were 'transiently lysogenized', but the rapid segregation prevents us from establishing this. The fact that the phage genome of $\varnothing X_{I}$ is transferred from Z2O-I, regardless of the marker selected, suggests that it is transferred independently of the chromosome. There have been two other reports of a phage genome being transferred from the donor during conjugation, independent of the host chromosome (Boice \& Luria, 1963; Sironi, Gallucci \& Maccacaro, 1964).

All recombinants from a $Z$ factor-mediated mating become donors. The $Z$ factor and chromosome might be transferred as separate genetic elements or together in some type of association. The observations that recipients become donors regardless of the marker selected and can become donors independent of genetic recombination support the first possibility. The latter possibility is supported by the results of u.v. irradiation in which donor ability is increased. Similar observations with the F factor have been interpreted to mean some kind of association with the chromosome (Evenchik, Stacey \& Hayes, 1969).

Attempts have been made to classify the $Z$ factor into one of the three major types, I, F (Lawn, Meynell, Meynell \& Datta, 1967) or N (Datta \& Hedges, 197I), based on phage growth experiments. Although $\mathrm{Z}^{+}$donors do support phage If I, so do the recipients which 
also support phage IKe (unpublished). This means that the pili which act as the receptor sites for these phages are not the sex pili for this intra-strain conjugation system.

Strains of CF2004-6 are competent recipients with donor strains of E. coli K I 2 (Zubrzycki \& Levinson, 1969). However, strains of Z2O are not donors with recipient strains of $E$. coli K I2 (Siegel \& Zubrzycki, 1968), or with E. coli B or C (unpublished). These negative results, at least between $\mathrm{Z} 20^{2}$ and $\mathrm{F}^{-}$strains of $E$. coli $\mathrm{KI} 2$, are not due to differences in host specificities, since $h s p \cdot \mathrm{CF}$ and $h s p \cdot \mathrm{K} \mathrm{I} 2$ are similar if not identical (Zubrzycki et al. 1972). Furthermore, $\mathrm{Z}^{+}$donors with $h s p \cdot \mathrm{Z}$ are as good if not better donors with CF2004-6 strains than those with $h s p \cdot C F$ (see Table 5). Experiments are being conducted to determine what accounts for the specificity between the donor and recipient strains of this conjugation system.

We acknowledge the technical assistance of Susan Levinson and Eileen Lowe during portions of this work. We thank the U.S. Public Health Service for a predoctoral award and training grant, GM-00983 (to D.S.) and for support of these investigations by a research grant, AI-0658I. Parts of this paper are taken from a Ph.D. thesis by D.S., submitted to Temple University, Philadelphia, U.S.A.

\section{REFERENCES}

ARber, W. \& Linn, S. (1969). DNA modification and restriction. Annual Review of Biochemistiy 38, 467-500. BHASKARAN, K. ( I 960). Recombination of characters between mutant stocks of Vibrio cholerae, strain I62. Journal of General Microbiology 23, 47-54.

Bhaskaran, K. \& Sinha, V. B. (I971). Transmissible plasmid factors and fertility inhibition in Vibrio cholerae. Journal of General Microbiology 69, 89-97.

Boice, L. B. \& Luria, S. E. (I963). Behavior of prophage PI in bacterial matings. I. Transfer of the defective prophage PI $d$ I. Virology 20, I47-I57.

Datta, N. \& Hedges, R. W. (I97I). Compalibility groups among $\mathrm{f}^{-} \mathrm{R}$ factors. Nature, London 234, 222-223.

Demerec, M., Adelberg, E. A., Clark, A. J. \& Hartman, P. E. (i966). A proposal for a uniform nomenclature in bacterial genetics. Genetics $\mathbf{5 4}, 6 \mathrm{I}-76$.

EvenchiK, Z., StACEY, K. A. \& HAYES, W. (1969). Ultraviolet induction of chromosome transfer by autonomous sex factors in Escherichia coli. Journal of General Microbiology 56, I-I4.

HAyes, W. (I952a). Recombination in Bact. coli KI2: unidirectional transfer of genetic material. Nature, London I69, I I 8--I I 9.

HAYES, W. (1952b). Genetic recombination in Bact. coli $\mathrm{K} 12$ : analysis of the stimulating effect of ultraviolet light. Nature, London 169 , IOI7.

Holloway, B. W., Krishnapillai, V. \& Stanisich, V. (1971). Pseudomonas genetics. Annual Review of Genetics 5, 425-426.

Lawn, A. M., Meynell, E., Meynell, G. G. \& Datta, N. (1967). Sex pili and the classification of sex factors in the Enterobacteriaceae. Nature, London 216, 343-346.

LederberG, J. \& TAtum, E. L. (1946). Novel genotypes in mixed cultures of biochemical mutants of bacteria. Cold Spring Harbor Symposia on Quantitative Biology 11, I I3-I 14.

Meynell, E., Meynell, G. G. \& Datra, N. (1968). Phylogenetic relationships of drug-resistance factors and other transmissible bacterial plasmids. Bacteriological Reviews 32, 55-83.

Novick, R. P. (1969). Extrachromosomal inheritance in bacteria. Bacteriological Reviews 33, $210-235$.

Pearce, L. E. \& Meynell, E. (1968). Specific chromosomal affinity of a resistance factor. Journal of General Microbiology 50, 159-172.

SiEgel, D. (1970). An intra-strain fertility system in Escherichia coli O4. Ph.D. thesis, Temple University, Philadelphia, Pennsylvania, U.S.A.

Siegel, D. \& Zubrzycki, L. (1968). An intra-strain fertility system in Escherichia coli O4. Bacteriological Proceedings, p. 63.

Sironi, G., Gallucci, E. \& Maccacaro, G. A. (1964). Possibility of conjugal infection by a male specific bacteriophage in E. coli. Giornale di Microbiologia 12, 196-198.

Stocker, B. A. D., Smith, S. M. \& Ozeki, H. (I963). High infectivity of Salmonella typhimurium newly infected by the coll factor. Journal of General Microbiology 30, 201-22 I. 
WAtAnABE, T. (1963). Episome-mediated transfer of drug resistance in Enterobacteriaceae. VI. Highfrequency resistance transfer system in Escherichia coli. Journal of Bacteriology 85, 788-794.

Zubrzycki, L., Green, J. \& Spaulding, E. H. (1966). A generalized transducing phage for a female Escherichia coli $\mathrm{O}_{4}$. Journal of General Microbiology 45, I I 3-1 22.

Zubrzycki, L. \& LeVInson, S. U. ( I969). Genetic heterology between Escherichia coli $\mathrm{k}$ I 2 and a smooth strain of E. coli. Journal of General Microbiology 57, I1 5-123.

Zubrzycki, L., Levinson, S. U. \& Siegel, D. (1972). The host specificities of the Z20 and CF2004-6 strains of an Escherichia coli $\mathrm{O}_{4}$ serotype. Journal of General Microbiology 71, 319-325. 